\title{
Efficacy of Geophysical Techniques for Groundwater Exploration in the Volta Basin, Northern Region of Ghana*
}

\author{
${ }^{1}$ A. Ewusi, ${ }^{1}$ J. Seidu and ${ }^{1}$ E. Ansah \\ ${ }^{1}$ University of Mine and Technology, P. O. Box 237, Tarkwa
}

Ewusi, A., Seidu, J. and Ansah, E. (2020), "Efficacy of Geophysical Techniques for Groundwater Exploration in the Volta Basin, Northern Region of Ghana”, Ghana Mining Journal, Vol. 20, No. 1, pp. 10 - 19.

\begin{abstract}
Groundwater, traditionally extracted from hand-dug wells and boreholes is the main drinking water source in the Northern Region of Ghana. Many boreholes have been constructed in the region to increase accessibility to potable water mainly as part of rural water supply projects where borehole siting has to be relatively cheaper. These projects have resulted in low success rates of borehole drilling because of the application of inefficient and simple geophysical techniques supposed to be cheaper. Field surveys were conducted with the Electrical Resistivity Imaging (ERI) technique, Electrokinetic System (EKS) sounding technique and Radon $\left({ }^{222} \mathrm{Rn}\right)$ technique with the objectives of determining the best geophysical methods for borehole siting and its efficiency in the Volta Basin (VB) in the Northern Region of Ghana. The surveys were conducted at stations of existing dry and positive boreholes. Results show that the three geophysical techniques are efficient to identify groundwater accumulation zones. The ERI, EKS and ${ }^{222} \mathrm{Rn}$ are efficient to identify discontinuities, calculate hydraulic conductivity of discontinuities and identify areas of water circulation respectively. It is recommended that the ERI be used to obtain discontinuities and weak zones for drilling on rural water supply projects in the VB. The EKS and ${ }^{222} \mathrm{Rn}$ should be conducted to evaluate these features when high yield boreholes are required.
\end{abstract}

Keywords: Geophysical Techniques, Volta Basin, Borehole Drilling, Success Rates

\section{Introduction}

The development of available groundwater resources is a significant aspect of the provision of potable water in urban and rural settings. For years, various geophysical techniques have been employed in the search for groundwater. In recent times however, technological advancements have brought about the use of state of the art geophysical techniques in groundwater exploration in complex terrains (Al-Garni, 2009). Groundwater, extracted from dug-outs, hand-dug wells and boreholes are the main drinking water sources for rural populations in the Northern Region of Ghana. Consequently, to increase access to this resource a number of hand dug wells and boreholes have been constructed in the region mainly as part of rural water supply projects. However, most of these rural water supply projects have encountered difficulties in boreholes siting. Most of the boreholes drilled are either dry or yields are less than $0.7 \mathrm{~m}^{3} / \mathrm{h}$, usual minimum yield for a hand-pump installation (Ewusi et al., 2009). Dapaah-Siakwan and GyauBoakye (2000) reported an overall success rate of $56 \%$ in the Volta Basin even though success rates are predominantly low in certain specific environments.

These low success rates were obtained using the common geophysical methods for rural water supply projects including the 4-electrode electrical resistivity survey (ERS) and Electromagnetic (EM) profiles to identify a discontinuity in the terrain, assuming that this discontinuity is representing a fractured zone. Vertical Electrical Sounding (VES) is then conducted to compare site potentials. This type of investigation is usually well adapted to the context of rural water supply projects which have tight budgetary allocations and so borehole siting should be rapid and low-cost. However, the very low success rates obtained with these methods in the Volta Basin in the Northern Region of Ghana requires that advanced geophysical methods are employed to increase the success rates of borehole drilling thereby reducing project implementation cost. The objective of this research therefore is to test the efficacy of the Electrical Resistivity Imaging (ERI), Electrokinetic System (EKS) and Radon techniques in the Volta basin in the Northern Region of Ghana.

\subsection{The Study Area}

The Northern Region is one of the administrative Regions of Ghana. The Region is rural, sparsely populated with underdeveloped infrastructure and services and has been identified as a critical water deficit area. Groundwater is not only feasible but also the most economic source of potable water due to the dispersed nature of the communities (GyauBoakye and Dapaah-Siakwan, 1999: Ewusi et al., 2009). Annual rainfall ranges between $1016 \mathrm{~mm}$ and $1600 \mathrm{~mm}$ with evapotranspiration averaging around $890 \mathrm{~mm}$ (Kwei, 1997). The climatic parameters of rainfall and potential evapotranspiration as well as the plant-soil complex and general slope are the major factors that influence groundwater recharge in the area. Because of the very high temperatures in the region, rainfall is usually evaporated back into the 
atmosphere with little water percolating for groundwater recharge (Ewusi, 2006). Acheampong (1988) observed that the Northern Region experiences long periods of dryness and the wet periods are only four months (July-November, except August) of the year. The inhabitants of the Northern Region of Ghana are mostly subsistence and peasant farmers, who grow crops such as maize, yam, peanuts and millet. Drainage in the area is enhanced by the Black and White Volta and the Oti Rivers (Akudago et al., 2009).

\subsection{Geology and Hydrogeology}

The Volta Basin (VB) has been stratigraphically divided into three (Fig. 1):

(i) Obosum Formation; consisting of dirtyyellow, fine-grained, thinly bedded, micaceous feldspathic quartz sandstones with subordinate argillite intercalations and whitish-yellow, massive fine to mediumgrained, cross-bedded arkosic and quartzose sandstone. This formation occurs as scattered outcrops in the central part of the Basin with an average thickness of $400 \mathrm{~m}$ (Darko, 2015).

(ii) Oti-Pendjari Supergroup; this group generally rests with angular unconformity on the Basal Sandstone and in some places rest directly on the basement. It is $1.5 \mathrm{~km}$ to $4 \mathrm{~km}$ thick and forms the most extensive sedimentary sequence in Ghana (Affaton, 2008). It consists of argillaceous sandstone, arkose, siltstones, interbedded mudstone, sandy shale, and conglomerates. The beds are generally gently dipping and very well consolidated rendering them inherently impermeable except at some few locations where weathering and fracturing induce secondary permeability (Dapaah-Siakwan and GyauBoakye, 2000). They are mainly fine and immature sediments deposited in a marine environment (Saunders, 1970).

(iii) Basal Sandstone; this is mainly a quartz sandstone formation about $75 \mathrm{~m}$ thick occurring at the northern and western peripheries of the Volta Basin. The Basal Sandstone is dominated by massive crossbedded feldspathic sandstones. It is flat-lying and intensely folded towards the Togo belt. A radiometric age of $993 \pm 62$ Ma gives the approximate beginning of the sedimentation for the lower part of the Volta Basin (Affaton, 2008). The deposition for the Basal Sandstone formation is likely to have been a shallow marine environment.

Generally, the Volta Basin has a very poor groundwater potential although some water supplies come from fractures in the argillaceous or loose zones in the arenaceous members (Chegbeleh et al., 2009). Regional hydrogeological studies have shown that fractures or joints in the area are erratic and even absent in some places. In isolated cases, the fractures are non-productive.

The area exhibits three classes of hydrogeological units, related to the geological settings:

(i) Very high groundwater potential areas; The Basal Sandstone, showing excellent prospects for groundwater.

(ii) Medium groundwater potential areas; The Oti-Pendjari Supergroup, showing moderate prospects for groundwater.

(iii) Very low groundwater potential areas; The Obosum Formation, showing poor prospects for groundwater.

These characteristics suggest that groundwater potential in the Volta Basin is diverse and requires thorough geophysical investigations to achieve high drilling success rates (Chegbeleh et al., 2009).

\section{Resources and Methods Used}

\subsection{ERI Technique}

The Electrical Resistivity Method is a versatile, fast and cost effective technique for mapping subsurface anomaly. Current is introduced into the ground and the resulting potential differences are measured. A geometric factor is used to convert the readings obtained into ground resistivity. A lund imagine system consisting of SAS ABEM Terrameter and ES464 switch box was used for data collection (Dahlin, 1996). The Lund system consists of a multielectrode arrangement for high resolution $2 \mathrm{D}$ and $3 \mathrm{D}$ resistivity surveys and is used for defining geological structures (Anon., 2007; Ewusi et al., 2009). Both horizontal and vertical variations in resistivity of the rocks are acquired with the instrument. Data is recorded automatically along the profile at the electrode stations and processed by the inversion software RES2DINV (Loke, 2004; Ewusi, 2009) which optimises the data to reduce the difference between the calculated and measured apparent resistivity values to a given root mean square (RMS) error by adjusting the resistivity of the model blocks. 


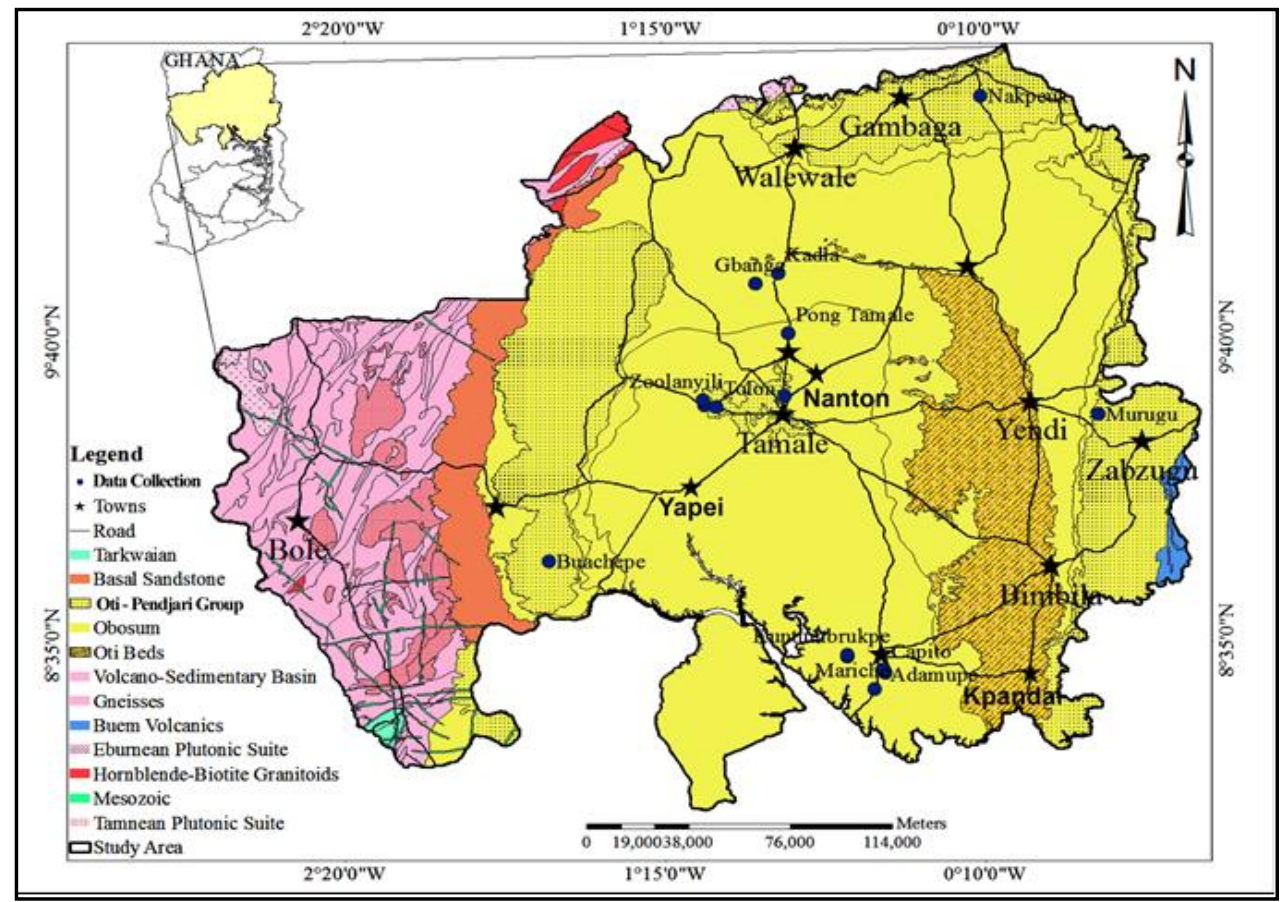

Fig. 1 Simplified Geological Map of the Study Area showing Locations of Geophysical Data Collection

\subsection{EKS Survey Technique}

The interpretation of surface data from "sounding mode" gives information about the permeability changes beneath the sounding location. The Groundflow (GF) 2500 was employed for the EKS data collection. The technique relies on the collection, processing and interpretation of electro seismic survey data using the GF 2500 system. The set is mounted in a vehicle for power, protection and transportation and consist of an electronic module and a computer, an antenna array and a seismic source. The equipment has standard PC controls and can be powered by mains power using the switch converter, internal lithium ion battery or directly from the cigarette lighter switch in a vehicle. A track pad is usually used instead of a mouse to ease field operations because operations with a mouse would make operations cumbersome in the field. Two seismic sources including the hammer and plate and buffalo gun for a higher energy seismic source can be used. Data is recorded from both dipoles inserted at both sides of the source. A two-fold data stacking is achieved by averaging the two processed channels in each data file. The data is collected at various stations and analysed to selected depths. Four electrodes are arranged in a straight line with two on either side of the source plate in the hammer and plate technique. The trigger is attached to the flat plane of the hammer and the other side of the hammer is used for the impact (Anon., 2004). The hammer and plate is quick and easy to use but is generally a weaker source and higher frequency component of the source energy will be lost in the soil if the water table is deep or if the surface material is unconsolidated making electro seismic signals more difficult to detect. The buffalo gun is recommended for all deep electro seismic surveying operations because it offers the most practical way of ensuring that the outgoing sound pulse is not attenuated by loose dry surface vegetation, soil or sand. With the hammer and plate seismic source which was applied in this research each sounding location is prepared by the removal of the top layer so that the plate could be set firm in the ground. Three data sets are recorded at each site location. Usually the second readings are used for processing because it is the reading where the plate is adequately embedded in the ground. Processing of field data is carried out by using parameters that have been chosen using all available hydrogeological information. These include source strength, depth to water table, and velocity of the various layers of rocks in the underneath the site. The velocity of the major rocks in the area is very important because it is used in the calculation of the potential yield of the site and so it requires detailed attention during data processing.

\subsection{Radon Technique}

$\mathrm{Rn}$ and $\mathrm{CO}_{2}$ have been used as tracer in hydrogeological studies especially for water well siting. Initially used in granitic and metamorphic contexts, prospecting ${ }^{222} \mathrm{Rn}$ anomaly is now also used in sedimentary terrains as the presence of radon is related to that of his parents (Uranium 238 and 234, Thorium 282 and Radium 225) which are 
present in practically all the rocks. The radon concentrations measured in the field, resulting from a single diffusion migration, depend on the intensity of the root source, the emissivity (ratio of the quantities of radon emitted to the quantities of radon released in the porosity) the source and terrain and the radioactive decay of radon. Thus, in very low-emitting soils like undisturbed clay, radon diffusion remains limited to a few centimeters. The presence of fracture increases radon concentration (Anon., 2004). The method consists of measuring the radon of the medium and identifying the areas of strongest radon activity. However, the quality of the results and their interpretation is delicate, as many artifacts can alter the results: poor control of sampling techniques, variations in atmospheric or/and meteorological conditions, radon parasite anomalies (uranium concentration) (Anon., 2004).

In this study detection of $\alpha$ by an instantaneous measurement (as opposed to integration measurements where detectors are left on site for 2 to 4 weeks) were applied. The samples are taken by means of a probe rod which is pushed into the ground to a depth of 0.60 to $0.70 \mathrm{~m}$. The air is then pumped with a hand pump and fed into a sample bottle. A sweep of the vial is performed to properly rinse the entire biopsy device. Approximately 4 litres of air is pumped for a $125 \mathrm{ml}$ sample volume. The sealed vial is then stored until analysis is done. The sample vial is actually an $\alpha$ detector consisting of an inert glass vial coated with silver-activated zinc-sulphide. This product has the property of absorbing the kinetic energy of particles $\alpha$ and transforming it into light energy. It is that amount of light that is measured and is proportional to the amount of radon. A radioactive decay correction is applied when calculating the radon content. It is very low in our case, since the storage time is very short usually a few hours. Results are expressed in $\mathrm{pCi} /$ litre or $\mathrm{Bq} / \mathrm{litre}(1 \mathrm{~Bq}=27 \mathrm{pCi})$.

\section{Results and Discussion}

Figs 2-4 show some results of ERI measurements in the VB. This technique is usually efficient when the drilling target is a vertical discontinuity. Fig. 2 shows a distinctively layered resistivity rocks with a low resistivity layer less than $20 \Omega$-m at the depth range $10 \mathrm{~m}$ to $30 \mathrm{~m}$ which reduces from $0 \mathrm{~m}$ to 400 $\mathrm{m}$ along the profile at Nanton profile F. Two boreholes were drilled on this profile. A borehole drilled at station $310 \mathrm{~m}$ beneath a vertical electrical discontinuity intercepted a sandstone layer with resistivity of about $300 \Omega-\mathrm{m}$ which accounted for the total yield of $1200 \mathrm{l} / \mathrm{min}$ of the borehole. A second well at F 160 produced a yield of $420 \mathrm{l} / \mathrm{m}$ with aquifer zones ranging from 23 to $50 \mathrm{~m}$.
In the ERI profile at Kpandai a low resistivity zone less than $200 \Omega-\mathrm{m}$ is observed at station $200 \mathrm{~m}$. In the Oti beds which is predominantly underlain by the basal sandstones the lower resistivity structures are interpreted as representing zones of potential groundwater occurrence. A well located at the station $230 \mathrm{~m}$ intercepted a fractured sandstone at a depth between $15 \mathrm{~m}$ and $35 \mathrm{~m}$ which accounted for the total yield of $420 \mathrm{l} / \mathrm{min}$ from the borehole. The station $200 \mathrm{~m}$ has similar resistive layers and are expected to give similar results. A high resistive zone was observed at the beginning of the profile from a depth of 20-50 m.

In the profile at Yapei three distinct resistive layers are identified: more than $100 \Omega-\mathrm{m}$, between 80 and $100 \Omega-\mathrm{m}$, and a low resistive layer less than $60 \Omega$ $\mathrm{m}$ are intercepted at depths (0-20) m. EKS surveys were carried out to obtain yield of some selected borehole stations in the VB to compare with yields obtained after these sites have been drilled. 12 sites were surveyed. Figs 5-7 illustrate representative selected EKS signals for high yields, medium yields and dry borehole signals in the area.

Fig. 5 show EKS survey results on a successful borehole at station Nanton (F160). Two evenly matched and a strong signal were obtained at depths $10 \mathrm{~m}$ to $30 \mathrm{~m}$. The yield calculated from the EKS was $160 \mathrm{l} / \mathrm{m}$. This zone however produced a yield of $170 \mathrm{1} / \mathrm{m}$ at a depth of $17 \mathrm{~m}$ from the records on the borehole. A second aquifer zone at depths of $45 \mathrm{~m}$ to $65 \mathrm{~m}$ from the EKS results did not contribute to the total yield of the borehole. The shallow depth yield obtained at a depth of $17 \mathrm{~m}$ contributed to the total yield of the borehole.

EKS sounding results on a successful borehole at Kpandai (C220) is shown in Fig. 6. The sounding produced two matched signals on both channels with high amplitude of hydraulic conductivity at the lower depth to a depth of about $30 \mathrm{~m}$ below ground level. The amplitude is very high at the depth range of $15 \mathrm{~m}$ to $30 \mathrm{~m}$. The deeper depth signal produced no significant amplitude indicating an absence of a probable aquifer. Because of the low static water level (SWL) in the area, hydraulic conductivity was not calculated above a shallow depth of $6 \mathrm{~m}$. Records on the borehole indicate a yield of $1800 \mathrm{l} / \mathrm{m}$ at depths of $15 \mathrm{~m}$ to $30 \mathrm{~m}$ as represented by high amplitude on the EKS signal. However, the EKS calculated a yield of $84 \mathrm{l} / \mathrm{m}$ for the borehole at that depth horizon. The major aquifer zone which contributed to the yield of the borehole was at a depth $24 \mathrm{~m}$ to $48 \mathrm{~m}$ from the results of actual drilling. This depth zone however did not show any significant yield from the EKS model results. 


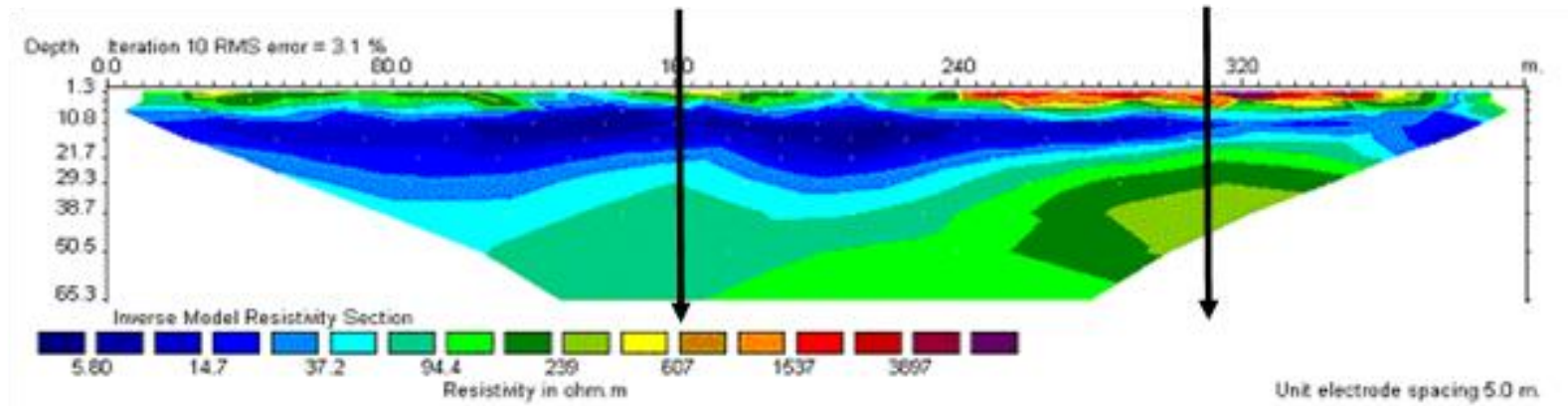

Fig. 2 Results of ERI Measurements on Profile F at Nanton

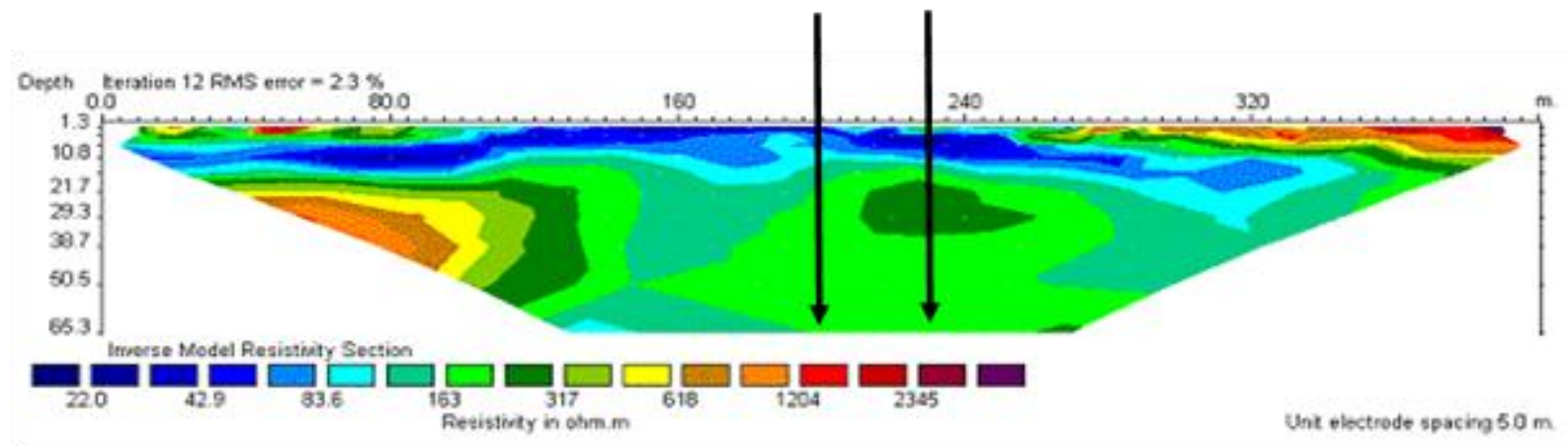

Fig. 3 Results of ERI Measurements on Profile C at Kpandai

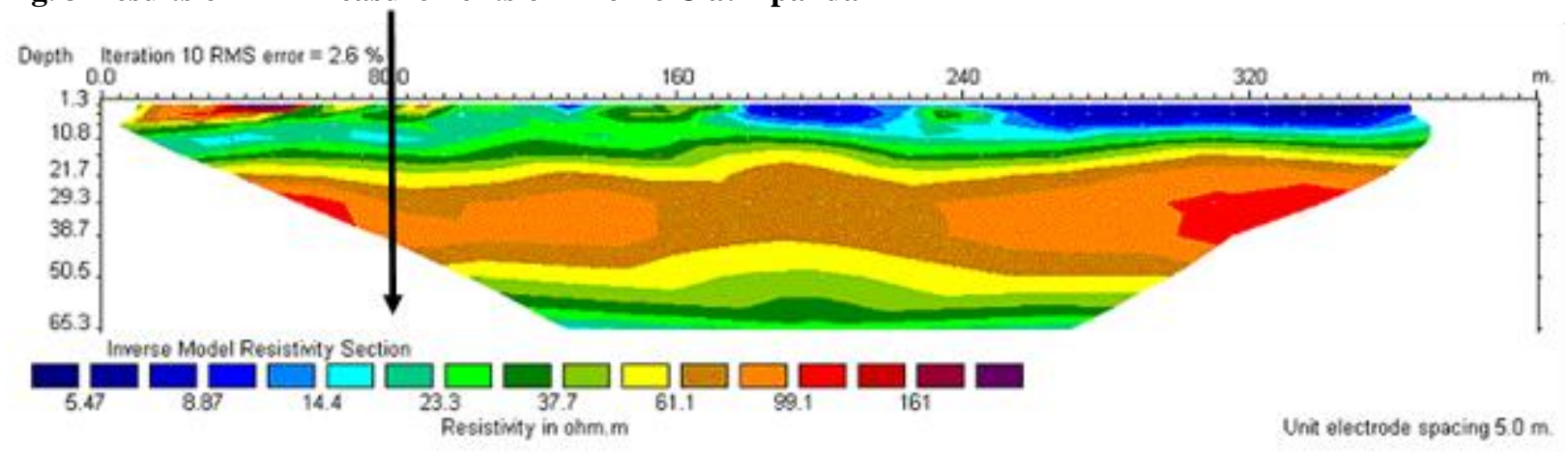

Fig. 4 Results of ERI Measurements at Yapei

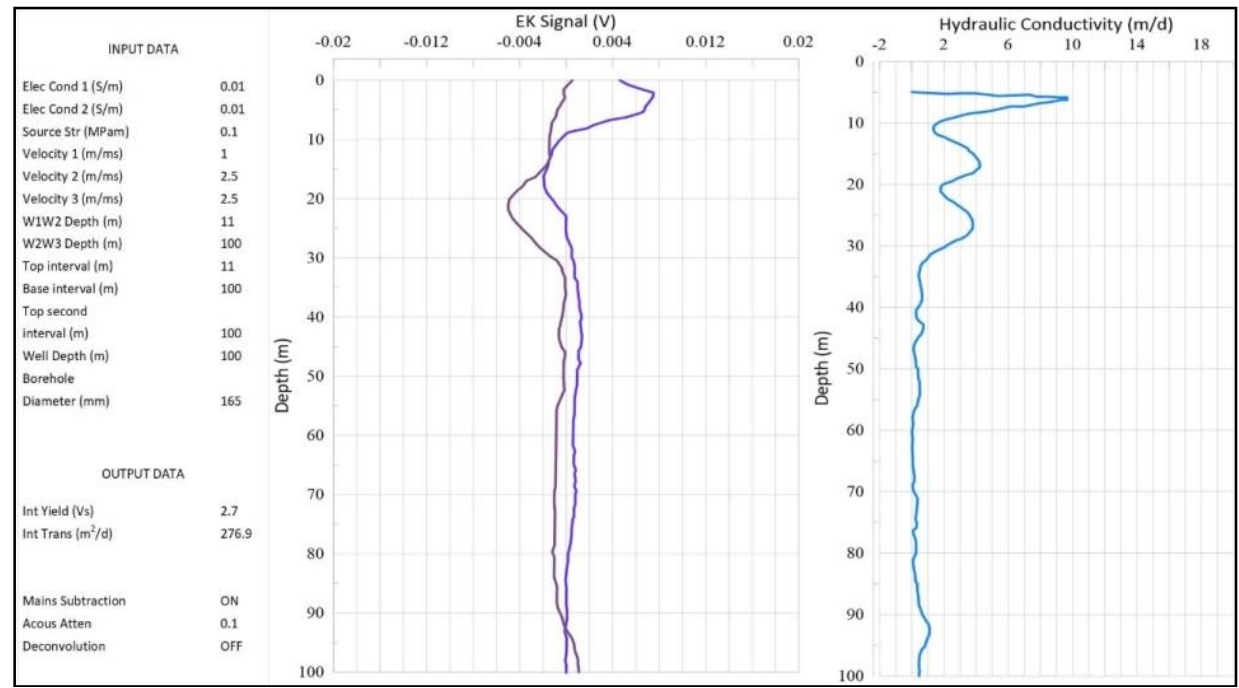

Fig. 5 EKS Sounding at F 160 (Nanton) 


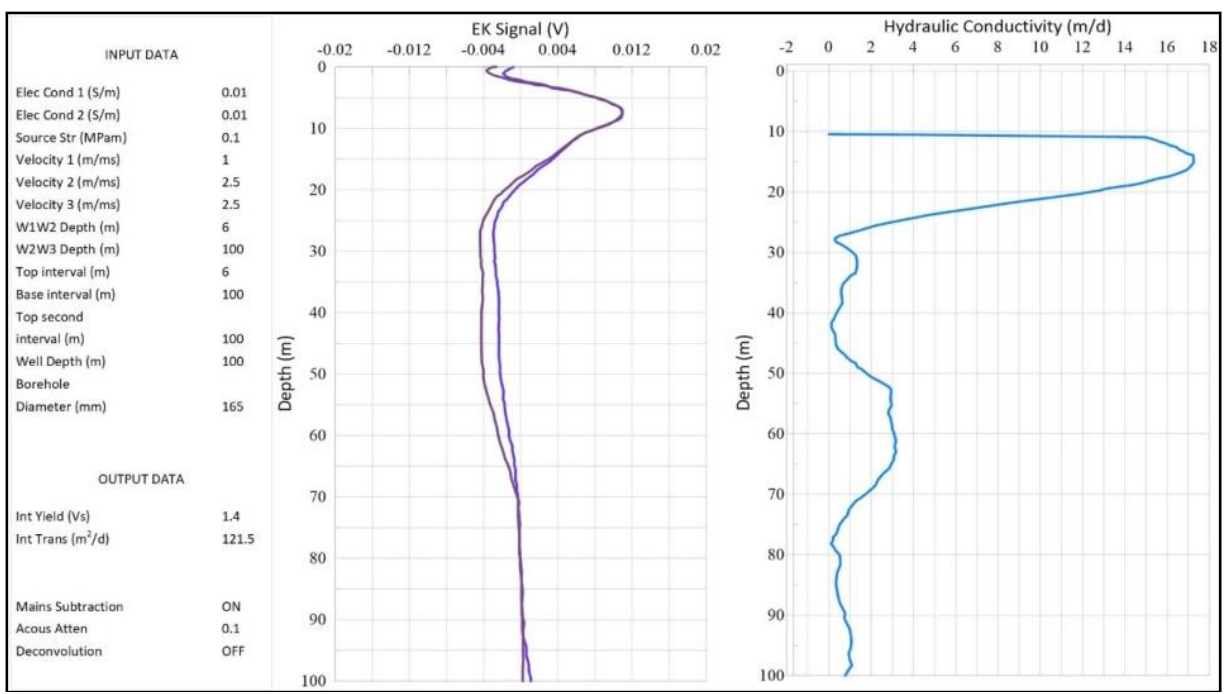

Fig. 6 EKS sounding at C 220 (Kpandai)

Fig. 7 shows EKS sounding data at station Yapei station C80. Very weak EKS signals were obtained at this station. As observed on the hydraulic conductivity curve, only a small extrapolated aquifer zone was observed at the depth range of 12 $\mathrm{m}$ to $30 \mathrm{~m}$. The hydraulic conductivity was very low with a calculated yield of $6 \mathrm{1} / \mathrm{m}$ which is considered as a dry well. The drilling at the station had a yield of $9 \mathrm{l} / \mathrm{m}$ at aquifer depths $15 \mathrm{~m}$ to $18 \mathrm{~m}$ and the EKS results calculated a yield of $18 \mathrm{l} / \mathrm{m}$.

The borehole yields and aquifer zones have also been summarised in Table 1. It is observed that in situations where the aquifer zones are less than 40 $\mathrm{m}$ the yield obtained from drilling and calculated EKS were very comparable. This is observed in Tolon (B195), Tolon A270 and marginal yields at Yarpei. It is also seen that the extreme results of the both EKS and actual drilling results occurred at
Naton (F160) and Kpandai (C220) which were both medium depth aquifer between $23 \mathrm{~m}$ to $50 \mathrm{~m}$.

Figs 8 and 9 show some results of Radon measurements in the VB which were carried out on dry and successful borehole sites. At Kadia, prospecting ${ }^{222} \mathrm{Rn}$ anomaly confirms that the dry borehole is very close to the target (Fig. 8) and also confirms the location of the positive borehole. The positive borehole has a radon concentration of $>20$ pCi/litre. At Kuntumprukpe, Fig. 8b, a positive well has a concentration of $14 \mathrm{pCi} /$ litre.

In Fig. 9a at Gbanga and it confirms the negative potentiality of the drilled zone. In Tolon, the survey confirms the existence of a permeable zone $50 \mathrm{~m}$ east of borehole BH1, as identified with the 2D profile (Fig. 9b). In Tolon, it shows that the high productive borehole is drilled in an anomaly zone, but not as close as possible to the center of the anomaly.

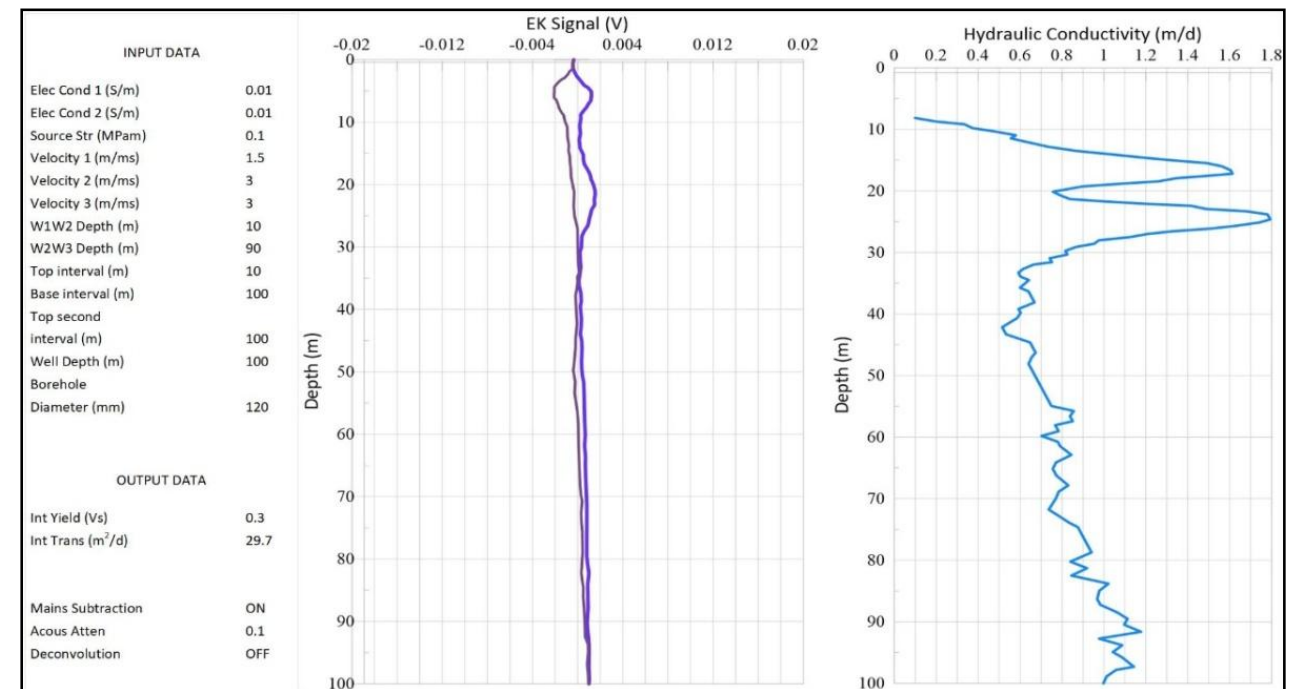

Fig. 7 EKS Sounding at C 80 (Yapei) 
Table 1 Borehole and EKS Yields

\begin{tabular}{|l|c|c|c|c|}
\hline Borehole Location & Drilling Yield (l/m) & EKS Yield (I/m) & Aquifer zones (m) & Final Depth (m) \\
\hline Pong Tamale (E155) & 15 & 12 & $20-25$ & 180 \\
\hline Pong Tamale (F40) & 2 & 3 & $15-20$ & 120 \\
\hline Diare (C195) & 58 & 96 & $27-42$ & 120 \\
\hline Nanton (F160) & 400 & 180 & $23-50$ & 60 \\
\hline Tolon (A270) & 38 & 24 & $15-24$ & 96 \\
\hline Tolon (B195) & 27 & 24 & $22-27$ & 57 \\
\hline Nyankpala (C380) & 5 & 2 & $14-18$ & 90 \\
\hline Yapei (E395) & 12 & 18 & $15-20$ & 120 \\
\hline Buipe (E125) & 12 & 18 & $15-25$ & 90 \\
\hline Yapei (C80) & 9 & 18 & $15-18$ & 75 \\
\hline Glubi Quarters (A265) & 40 & 246 & $62-74$ & 60 \\
\hline Kpandai (C200) & 420 & 84 & $24-48$ & \\
\hline
\end{tabular}

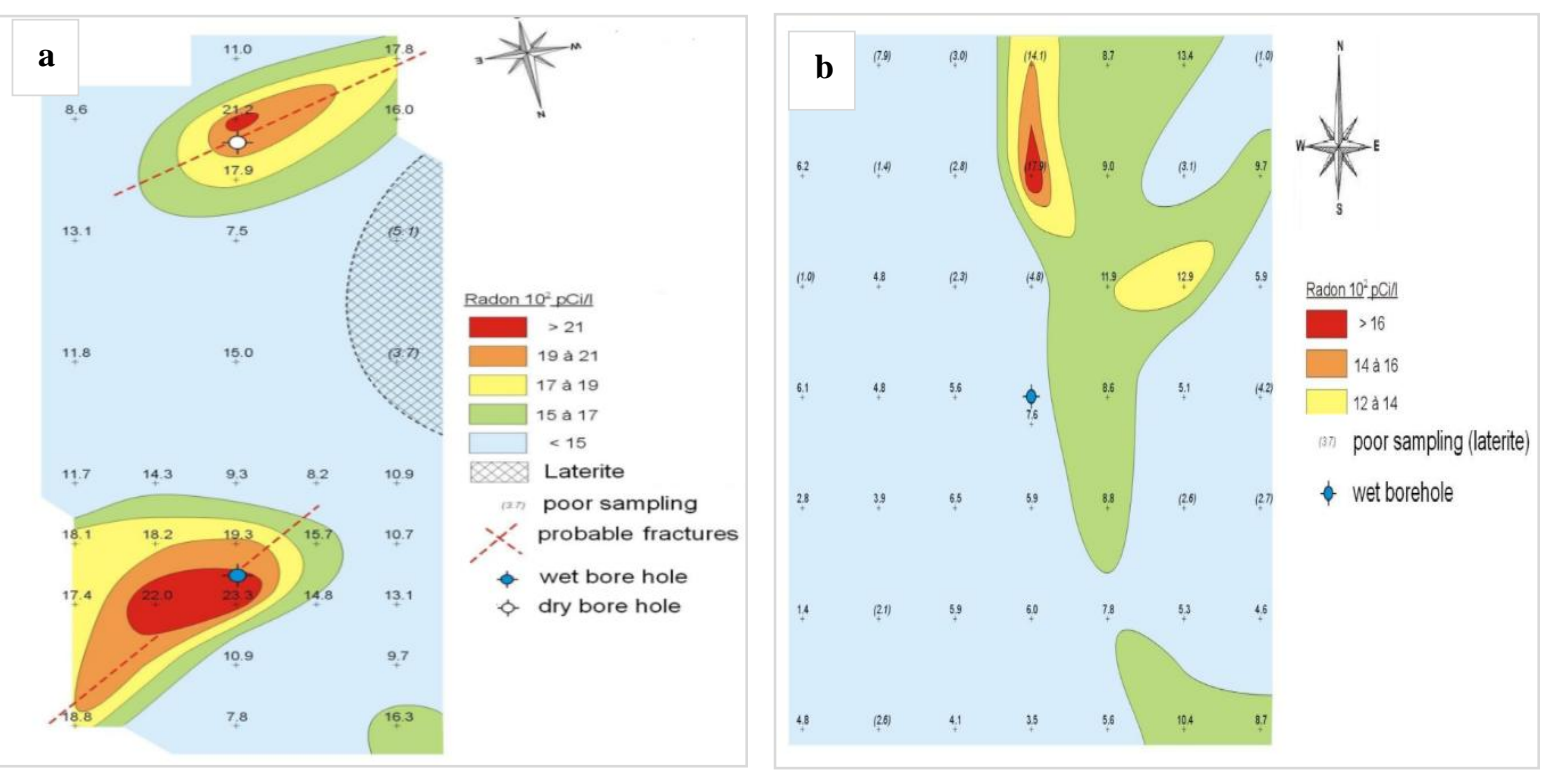

Fig. 8 Radon Results at (a) Kadia and (b) Kuntumprukpe
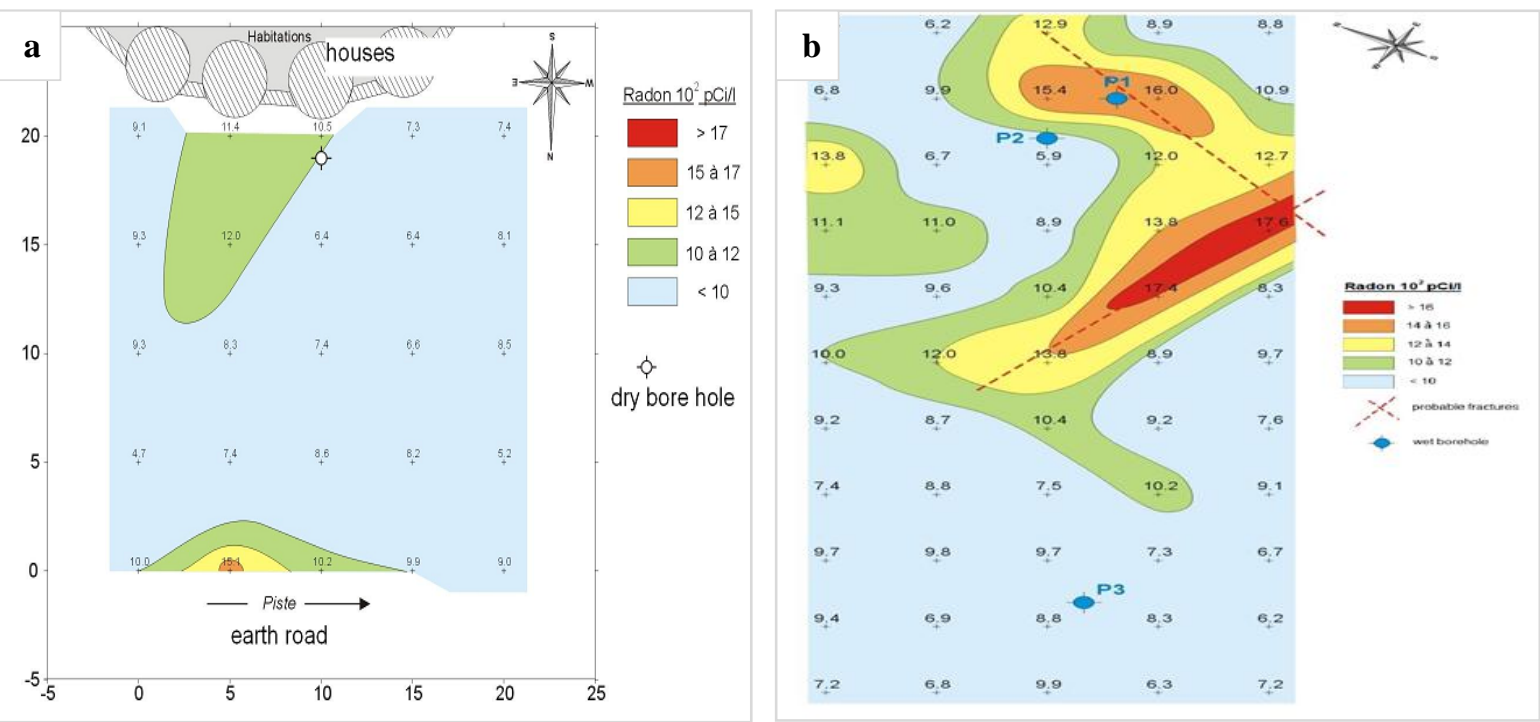

Fig. 9 Radon Results at (a) Gbanga and (b) Tolon 


\section{Conclusions}

The results from this study demonstrate the efficiency of such investigations. It shows that the negative boreholes were never drilled beneath an electrical anomaly. Such negative sites would have never been selected for drilling using these techniques.

The methods tested are efficient to identify fractures, their extension in depth and to evaluate their hydraulic conductivity. They clearly show that the hydrogeological target for drilling can be both vertical and horizontal discontinuities:

(i) The research shows no example of positive borehole drilled beneath large vertical discontinuities, because this type of target cannot be sited with precision using the old and common methods which had been used to site boreholes in the area.

(ii) The research also show that the low resistive formations can be positive or negative depending on the rocks in the area (in term of borehole productivity) and the ERI alone cannot differentiate this but EKS can be used to calculate the hydraulic conductivity.

(iii) The research demonstrated the sensitivity of the radon technique for locating fault or fracture systems when masked by unconsolidated cover (weathered sandstone). The study also showed that at least about 200 samples are necessary in a survey for the selection of a potential borehole-drilling site.

It can be concluded from these results that the ERI can be used to demarcate fractures and weak zones for groundwater accumulation, EKS is effective in demarcating aquifer zones between $5 \mathrm{~m}$ to $25 \mathrm{~m}$. This is quite good because the VB is dominated by very shallow aquifers and also when there is no EKS signal and the calculated yield is less than 10 $1 / \mathrm{m}$ then there is the possibility of a marginal or dry borehole underneath the station. Also, the yield obtained from the EKS surveys was not accurate and this could be attributed to using a general velocity value for in-putting parameters into the software.

\section{References}

Acheampong, P. K. (1988), "Water balance analysis for Ghana, Geography, Vol. 73, No. 2, pp. 125-131.

Affaton, P. (2008), "Lithostratigraphy of the Volta Basin and Related Structural Units", The Volta Basin, Ghana, Workshop and Excursion,
Abstract Volume, Geological Survey of Denmark and Greenland, Copenhagen, pp. 1317.

Akudago, J. A., Chegbeleh, L. P., Nishigaki, M., Nanedo, N. A., Ewusi, A. and Kankam-Yeboah, K. (2009). "Borehole Drying: A Review of the Situation in the Voltaian Hydrogeological System in Ghana", Journal of Water Resource and Protection, Vol.1, No.3, pp. 153-163.

Al-Garni, M. A. (2009), “Geophysical investigations for groundwater in a complex subsurface terrain, Wadi Fatima, KSA: A case history", Jordan Journal of Civil Engineering, Vol. 3, No. 2, pp. 118-136.

Anon, 2007, ABEM Instruction Manual for SAS 1000/4000 Terameter, ABEM Instrument ABS17266 Sundbyberg, Sweden, $135 \mathrm{pp}$

Anon. (2000), International Development Agency (IDA) funded 80 borehole drilling program, Unpublished Technical Report, Unihydro Limited 150pp.

Anon. (2004), "EKS pilot study in the northern region of Ghana" Unpublished Technical Report, Unihydro Limited, Ghana, 80 pp.

Chegbeleh, L. P., Akudago, J. A., Nishigaki, M. and Edusei, S. N. K. (2009), "Electromagnetic Geophysical Survey for Groundwater Exploration in the Voltaian of Northern Ghana", Journey of Environmental Hydrology, Vol. 17, No. 9, 16pp.

Dahlin, T., 1996. "2D resistivity surveying for environmental and engineering applications" First Break, Vol. 14, pp. 275-284.

Dapaah-Siakwan, S. and Gyau-Boakye, P. (2000), "Hydrogeologic Framework and Borehole Yields in Ghana", Hydrogeology Journal, Vol. 8, No. 4, pp. 405-416.

Darko, E. (2015), "Hydrogeological Characterisation of the White Volta River Basin of Ghana", Unpublished MPhil Thesis, University of Ghana, Ghana, 99 pp.

Ewusi, A, Kuma, J. S. Y., Hans J., Voigt, H. J. (2009), "Utility of the 2-D Multi-Electrode Resistivity Imaging Technique in Groundwater Exploration in the Voltaian Sedimentary Basin, Northern Ghana", Natural Resources Research, Vol. 18, No. 4, pp. 267-275.

Ewusi, A. (2006), "Groundwater exploration and management using geophysics in the Northern Region of Ghana", Unpublished PhD Thesis: Brandenburg Technical University, Chair of Environmental Geology, Germany, 171pp.

Kwei, C. A. (1997), "Evaluation of groundwater potential in the Northern Region of Ghana", Canadian International Development Agency (CIDA) Accra, Ghana, pp. 69.

Loke, M. H. (2004), Tutorial: 2-D and 3-D electrical imaging surveys, Published Notes, $136 \mathrm{pp}$. 
Saunders, R.S. (1970), "Early Paleozoic Orogeny in Ghana: Foreland Stratigraphy and Structure", Geological Society of America, Vol. 81(1), pp. 233-240.

\section{Authors}

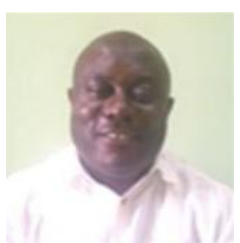

A. Ewusi is an Associate Professor of Hydrogeology at the University of Mines and Technology, Tarkwa, Ghana. He holds a $\mathrm{PhD}$ in Hydrogeophysics and an MSc in Environmental Resources Management (Hydrogeology) from the Brandenburg University of Technology,

Germany. He obtained a BSc (Hons) Geological Engineering from the Kwame Nkrumah University of Science and Technology (KNUST), Kumasi, Ghana. His research interests are in Groundwater management and Geophysics.

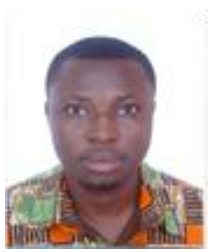

J. Seidu is a Lecturer at the University of Mines and Technology (UMaT), Tarkwa. $\mathrm{He}$ has an MPhil and BSc (Hons) in Geological Engineering from UMaT. His research interests are in Groundwater Studies, Geophysics and Water Resources Management.

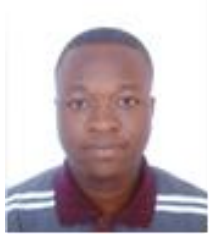

E. Ansah is a Demonstrator at the Petroleum Engineering Department. at the University of Mines and Technology (UMaT), Tarkwa. He is currently pursuing an MPhil in Petroleum Engineering at UMaT. His research interests are in Reservoir Characterisation, Exploration Geophysics, Water Resources Management and Petroleum Geology. 